\title{
Increased number of retinal vessels in acromegaly
}

\author{
Laila Füchtbauer2, Daniel S Olsson ${ }^{1,2}$, Eva C Coopmans ${ }^{3}$, Bengt-Âke Bengtsson ${ }^{1,2}$, Lise-Lott Norrman ${ }^{4}$, \\ Sebastian J C M M Neggers ${ }^{3}$, Ann Hellström ${ }^{5}$ and Gudmundur Johannsson ${ }^{1,2}$
}

${ }^{1}$ Department of Internal Medicine and Clinical Nutrition, Institute of Medicine, Sahlgrenska Academy, University of Gothenburg, Gothenburg, Sweden, ${ }^{2}$ Department of Endocrinology, Sahlgrenska University Hospital, Göteborg, Sweden, ${ }^{3}$ Pituitary Center Rotterdam, Endocrinology Section, Department of Internal Medicine, Erasmus University Medical Center, Rotterdam, The Netherlands, ${ }^{4}$ Department of Internal Medicine, Södra Älvsborgs Sjukhus, Borås, Sweden, and ${ }^{5}$ Department of Ophthalmology, Institute of Neuroscience and Physiology, Sahlgrenska Academy, The Queen Silvia Childrens' Hospital, Göteborg, Sweden

Correspondence should be addressed to L Füchtbauer Email laila.fuchtbauer@vgregion.se

\begin{abstract}
Objective: Excess of growth hormone (GH) and insulin-like growth factor 1 (IGF-1), as in acromegaly, is associated with increased risk of diabetes, but whether retinal vessels are altered is unknown. The aim of this study was to evaluate retinal vessel morphology in patients with acromegaly at diagnosis and after treatment and to describe the prevalence of diabetic retinopathy in patients with long-standing acromegaly and diabetes.

Design: Two independent observational studies, one being prospective and the other retrospective and cross-sectional. Methods: Retinal vessel morphology of 26 patients with acromegaly was examined at diagnosis and 1 year after treatment and compared to 13 healthy controls. Cross-sectional evaluation of 39 patients with long-standing acromegaly and diabetes was performed. Fundus photographs were digitally analyzed for vessel morphology. Results: Patients with acromegaly had a median (interquartile range) of 34.3 (30.0-39.0) vessel branching points compared to 27.0 (24.0-29.0) for healthy controls $(P<0.001)$. Tortuosity of arterioles and venules remained unchanged. Vessel morphology did not change significantly after treatment. Patients with acromegaly and diabetes for a median of 14 years also had a high number of branching points (34.2 (32.5-35.6)), but the prevalence of diabetic retinopathy was not higher than expected in diabetic patients without acromegaly.

Conclusions: Patients with acromegaly have an increased number of vascular branching points in the retina without an alteration of macroscopic vessel morphology. This is consistent with an angiogenic effect of GH/IGF-1 in humans. The prevalence of diabetic retinopathy was not increased in patients with acromegaly and diabetes.
\end{abstract}

\section{Introduction}

Patients with acromegaly have elevated serum concentrations of growth hormone (GH) and insulin-like growth factor 1 (IGF-1), which is associated with excess mortality, mainly due to cardiovascular diseases (1). There is evidence that normalization of GH and IGF-1 levels negates the increased mortality of the condition (2). As the disease develops slowly and initially has unspecific symptoms, diagnosis is often delayed by many years. Increased GH exposure in acromegaly leads to insulin resistance (3) with hypertension and diabetes mellitus (DM) among the main comorbidities affecting patients (4).

Patients with DM may develop microangiopathy with abnormal vessel growth and permeability, which can affect various organs. Presence and severity of changes in the retina may predict changes in other organs (5). The retina therefore provides a unique possibility to study microvascular morphology by direct and non-invasive examination.

Published by Bioscientifica Ltd. 
The roles of GH and IGF-1 as trophic factors in the eye have been discussed in this context. As insulin inhibits IGF-binding protein-1 (IGFBP-1) and induces hepatic production of IGF-1, patients with type $1 \mathrm{DM}$ have low serum levels of IGF-1 and increased IGFBP-1 and GH levels (6). In type $2 \mathrm{DM}$, the situation is more complex, but most studies in type $2 \mathrm{DM}$ find serum IGF-1 levels comparable to healthy controls $(7,8)$. Correlations between serum IGF-1 concentrations and the presence and severity of diabetic retinopathy have shown conflicting results (9, 10), but high levels of intravitreous IGF-1 have been seen in patients with proliferative retinopathy (11).

Early reports of improvement of diabetic retinopathy after pituitary infarction or ablation in patients with type 1 DM $(12,13)$ may support the hypothesis of a pathogenic role of GH and IGF-1 in diabetic retinopathy. We would therefore expect that patients with active acromegaly and diabetes would have a higher prevalence of diabetic retinopathy; however, previous small studies have not consistently shown this $(14,15,16)$.

The aim of this study was, for the first time, to evaluate retinal vessel morphology by an objective method using digital imaging analysis of fundus photographs in patients with acromegaly at diagnosis and after biochemical control. In a different cohort of patients with long-standing acromegaly and type $2 \mathrm{DM}$, we aimed to describe retinal findings and the prevalence of diabetic retinopathy.

\section{Subjects and methods}

\section{Study protocol}

This report contains two independent studies. The first is a case-control study followed by a prospective cohort study of retinal vessel morphology in patients with acromegaly. The second is a retrospective cross-sectional study on retinal findings in patients with long-standing acromegaly and type $2 \mathrm{DM}$. In the first study, patients were included in Gothenburg, Sweden, at the time of diagnosis when fundus photographs were taken before any type of intervention. Measurements were compared to healthy controls. Patients were then treated according to best clinical practices, with surgery, medical treatment, or both. If necessary, patients received hormonal replacement therapy (Table 1). Follow-up fundus photographs were available in 16 patients after a median time of 1.4 years (range, 0.8-3.5). In the second study, fundus photographs at a regular check-up of patients with long-standing and well-treated acromegaly and type 2 DM were examined in patients from Rotterdam, the Netherlands.

\section{Subjects}

Recruitment of 26 consecutive patients with acromegaly was performed at the Sahlgrenska University Hospital (Gothenburg, Sweden) between 2004 and 2011. Acromegaly was diagnosed by the presence of clinical features, serum IGF-1 levels 1.2 times above the ageadjusted upper limit of normal (ULN), GH nadir $>1 \mu \mathrm{g} / \mathrm{L}$ after oral glucose tolerance test (OGTT), or GH-day curve with a minimum value $>1 \mu \mathrm{g} / \mathrm{L}$ in the presence of a pituitary adenoma. GH-day curve, OGTT, and serum IGF-1 measurements were performed at follow-up. Patients were considered to have controlled disease if two or more of these tests were normal.

For the cross-sectional study, clinical data and fundus findings at the last clinical check-up (as of September 2018) were obtained for patients at the Erasmus University Medical Center (Rotterdam, the Netherlands). Fundus photographs were dated between 2005 and 2018 in this part of the study.

\section{Reference populations}

Results were compared with fundus photographs of 13 healthy adults of similar age as the acromegalic patients. As fundus morphology of healthy individuals does not change after 3 years of age (17), the acromegalic patients in this study were also compared to normal fundus photographs from 100 young (3-19 years of age), healthy individuals who were analyzed with the same equipment (18).

For comparison of the prevalence of diabetic retinopathy, we used data from the Swedish National Diabetes Registry. We extracted data on diabetic retinopathy during 2018 for patients with type 2 DM treated in primary care with a disease duration of 7-14 years. This analysis was conducted at both a nationwide level and a regional level, including 121603 and 22564 patients, respectively, with a completeness for data of $86 \%$ and $81 \%$, respectively (19).

\section{Ethical considerations}

Informed consent was obtained from all patients. The study was approved by the Regional Ethics Review Boards/ Local Institutional Review Boards in Gothenburg, Sweden, and in Rotterdam, the Netherlands. 
Table 1 Characteristics of acromegalic patients from Gothenburg and Rotterdam.

\begin{tabular}{|c|}
\hline Characteristics \\
\hline Sex, $n(\%)$, Male/Female \\
\hline Median age at diagnosis, year (range) \\
\hline Median age at follow-up, year (range) \\
\hline Adenoma type, $n(\%)$, micro/macro \\
\hline Treatment at diagnosis, $n(\%)$ \\
\hline Surgery \\
\hline Somatostatin receptor ligands \\
\hline Dopamine agonist \\
\hline Pre-operative treatment, $n(\%)$ \\
\hline Somatostatin receptor ligands \\
\hline Pegvisomant \\
\hline Dopamine agonist \\
\hline Current treatment, $n(\%)$ \\
\hline Somatostatin receptor ligands \\
\hline Pegvisomant \\
\hline Dopamine agonist \\
\hline Radiotherapy \\
\hline Mean IGF-1, xULN (S.D.) \\
\hline Mean BMI, kg/m² (s.D.) \\
\hline Diabetes, $n(\%)$ \\
\hline Impaired glucose tolerance, $n(\%)$ \\
\hline Mean fasting glucose, mmol/L (s.D.) \\
\hline Mean glucose $2 \mathrm{~h}$ after OGTT, $\mathrm{mmol} / \mathrm{L}$ (S.D.) \\
\hline Mean $\mathrm{HbA} 1 \mathrm{c}$ at last follow-up, \% (s.D.) \\
\hline Mean SBP/DBP, mmHg (S.D.) \\
\hline Mean total cholesterol, mmol/L (s.D.) \\
\hline Mean LDL-cholesterol, mmol/L (S.D.) \\
\hline Mean HDL-cholesterol, mmol/L (s.D.) \\
\hline Mean triglycerides, $\mathrm{mmol} / \mathrm{L}$ (s.D.) \\
\hline Treatment with statin/RAS inhibitor, $n(\%)$ \\
\hline Ischemic heart disease, $n(\%)$ \\
\hline Hormone insufficiency, $n(\%)$ \\
\hline Thyroid hormone \\
\hline Testosterone \\
\hline Estrogen \\
\hline Adrenocorticotropic hormone \\
\hline Hormone replacement, $n(\%)$ \\
\hline Thyroid hormone \\
\hline Testosterone \\
\hline Estrogen \\
\hline Hydrocortisone \\
\hline
\end{tabular}

\begin{tabular}{c}
\hline Gothenburg patients $(n$ \\
\hline $13(50) / 13(50)$ \\
$47.9(23-75)$ \\
$51.0(31-73)$ \\
$5(19) / 21(81)$ \\
$23(63.9)$ \\
$2(7.7)$ \\
$1(3.8)$
\end{tabular}

$$
\begin{aligned}
& 3(11.5) \\
& 0
\end{aligned}
$$

$$
-
$$$$
-
$$$$
-
$$

$3.20(1.32)$

26.7 (4.2)

7 (26.9)

6 (23.1)

$6.2(2.3)$

$9.6(4.5)$

ND

$136(17) / 79(11)$

$5.0(0.8)$

$2.3(1.3)$

$1.5(0.3)$

$1.5(1.1)$

2 (8)/5 (19)

$1(3.8)$

$4(15.4)$

6 (23.1)

4 (15.4)

0

$2(7.7)$

1 (3.8)

\begin{tabular}{|c|}
\hline Rotterdam patients $(n=39)$ \\
\hline $\begin{aligned} 23 & (59) / 16(41) \\
45.9 & (18-69) \\
60.2 & (33-84) \\
1 & (3) / 38(97)\end{aligned}$ \\
\hline $\begin{array}{c}24(61.5) \\
\text { NR } \\
\text { NR }\end{array}$ \\
\hline $\begin{array}{c}18(46.2) \\
6(15.4) \\
0\end{array}$ \\
\hline $\begin{array}{c}35(89.7) \\
33(84.6) \\
3(7.7) \\
4(15.4)\end{array}$ \\
\hline $\begin{array}{c}0.92(0.38) \\
30.6(4.2) \\
39(100)\end{array}$ \\
\hline $\begin{array}{r}\text { ND } \\
\text { ND } \\
\text { ND }\end{array}$ \\
\hline $\begin{array}{l}6.8(0.9) \\
135(11) / 83(10) \\
4.6(1.0) \\
2.8(0.8) \\
1.4(0.5) \\
1.4(0.6) \\
23(59) / 25(64) \\
\text { NR }\end{array}$ \\
\hline $\begin{array}{r}9(23.1) \\
16(41.0) \\
8(20.5) \\
6(15.4)\end{array}$ \\
\hline $\begin{aligned} 9 & (23.1) \\
14 & (35.9) \\
2 & (5.1) \\
6 & (15.4)\end{aligned}$ \\
\hline
\end{tabular}

1 (3.8)

0

One additional Swedish patient received thyroxine after thyroid surgery.

DBP, diastolic blood pressure; HbA1c, glycated hemoglobin A1c; HDL, high-density lipoprotein; LDL, low-density lipoprotein; ND, not done; NR, not reported; OGTT, oral glucose tolerance test; RAS, renin-angiotensin system; SBP, systolic blood pressure; ULN, upper limit of normal.

\section{Biochemical analysis}

The technique for measuring serum IGF-1 concentrations changed during the study period. The individual results were therefore compared to the age- and sexmatched/adjusted reference ranges supplied by the producer to acquire a percentage of the ULN. In Sweden before September 2006, serum IGF-1 was measured using a chemiluminescent immunoassay (Advantage, Nichols Institute Diagnostics, San Juan Capistrano, CA). After September 2006, an Immulite automated chemiluminescence system was used (Immulite 2500/200Xpi, Siemens Medical Solutions Diagnostics). The method for measuring serum GH also changed during the study period. Before 2008, an immunofluorometric assay was used (DELFIA ${ }^{\circledR}$, Wallac, Sweden), whereas after 2008, a one-step immunoenzymatic method was used (Access2, Beckman Coulter, Bromma, Sweden).

In the Netherlands before 2013, serum IGF-1 was measured with the Immulite 2000 assay (DPC Biermann $\mathrm{GmbH} /$ Siemens), which is a solid-phase, enzyme-labeled chemiluminescent immunometric assay with an intra- 
assay variability of $2-5 \%$ and an inter-assay variability of 3-7\%. IGF-1 age- and sex-adjusted reference ranges were used from the publication by Elmlinger et al. (20). From 2013, serum total IGF-1 concentrations were analyzed by the commercially available immunometric assay (IDSiSYS, Immunodiagnostic Systems Limited, Boldon, UK), which has intra-assay and inter-assay coefficients of variation for IGF-1 of $8.1 \%$ and $2.1 \%$, respectively, using recently reported reference intervals (21).

\section{Fundus photography and digital image analysis}

In Sweden, fundus photographs were taken with a Canon $60^{\circ}$ fundus camera (CF-60UD) and developed as dias slides. These were then digitalized by a CCD flatbed scanner and analyzed by a computer-assisted digital mapping system as described previously (22). Briefly, the retinal vessels (arteries, veins, and unspecified small vessels) were traced manually from their origin on the optic disc to a reference circle $3.0 \mathrm{~mm}$ from the geometric center of the optic disc. Tortuosity index was obtained by dividing the vessel's path length by the linear distance from its origin to the reference circle. The number of branching points on all vessels within the reference circle were identified manually and counted automatically. In the Netherlands, fundus photographs were taken locally for clinical diabetic retinopathy assessment and, thus, by different cameras and at different angles. Some were analyzed manually and some digitally.

\section{Conventional retinal analysis}

All fundus photographs were thoroughly analyzed in a masked fashion with respect to acromegalic patients and controls by two independent ophthalmologists. If there was disparity between the retinal evaluation, a consensus was reached. The optic disc was analyzed for glaucoma and retina for abnormal retinal vessel appearance, where abnormalities associated with hypertension were graded according to the Keith-Wagener-Barker classification (23), and abnormalities associated with diabetic retinopathy were graded according to the modified Airlie House classification. In addition, macular morphology abnormalities were noted.

\section{Statistical analysis}

The primary outcome measures of this study were retinal vascular branching points and tortuosity index of arterioles and veins. Secondary outcome measures were the prevalence of diabetes retinopathy, morphometric measures of the optic disc, and prevalence of other retinopathies.

Since the size of the groups were limited, results for retinal measurements are shown as median and interquartile ranges (IQRs). Comparison of results to the reference populations was performed using the nonparametric Mann-Whitney $U$-test. For the follow-up analyses, the results were compared using a two-tailed Wilcoxon signed-rank test. Adjusted analyses for age and sex were performed using regression models (ANOVA). $P$ values of $<0.05$ were considered significant. IBM SPSS (version 21; SPSS Institute) software was used to perform the statistical analyses.

\section{Results}

\section{Baseline}

The clinical characteristics of patients with acromegaly from Gothenburg $(n=26)$ and Rotterdam $(n=39)$ are summarized in Table 1. At diagnosis, in the Gothenburg cohort, 13 patients had abnormal glucose metabolism, one patient had type $1 \mathrm{DM}$, six patients had type $2 \mathrm{DM}$, and six patients had impaired glucose tolerance following OGTT. All patients from Rotterdam had type 2 DM and acromegaly. Morphometric measurements of the retinal vessels of 26 patients with untreated acromegaly and 13 healthy controls are shown in Table 2. An example of a fundus photograph is shown in Fig. 1. Retinal vessel tortuosity and optic disc dimensions did not differ between cases and controls. Compared to healthy adult and child controls, patients with acromegaly had an increased number of retinal vessels as reflected by more branching points. Patients with hypertension (systolic blood pressure >135 $\mathrm{mmHg}$ ) and abnormal OGTT including DM did not differ in number of branching points from patients without these abnormalities (data not shown). There was no correlation between serum IGF-1 levels or age and number of retinal vascular branching points (Pearson's coefficient 0.15 and -0.12 , respectively). Eighteen of the acromegalic patients had a normal retina, two had grade 1 hypertensive retinopathy, three had pre-proliferative diabetic retinopathy (one had previously been laser treated), one had glaucoma, and two had macular abnormalities. Conventional analysis of the fundus photographs was normal for the healthy controls. 
Table 2 Retinal vessel and optic nerve morphometry.

\begin{tabular}{|c|c|c|c|c|}
\hline & \multicolumn{3}{|c|}{ Gothenburg } & \multirow[b]{2}{*}{ Rotterdam $(n=39)$} \\
\hline & Patients $(n=26)$ & Controls $(n=13)$ & $P$ values patients vs adult controls & \\
\hline \multicolumn{5}{|l|}{ Sex, $n(\%)$} \\
\hline Men & $13(50)$ & $4(30.8)$ & & $23(59.0)$ \\
\hline Women & $13(50)$ & $9(69.2)$ & & $16(41.0)$ \\
\hline Median age, year (range) & $47.9(23-75)$ & $53.8(32-67)$ & & $60.2(33-84)$ \\
\hline \multicolumn{5}{|l|}{ Median tortuosity index (IQR) } \\
\hline Arteries & $1.06(1.05-1.08)$ & $1.06(1.05-1.07)$ & 0.6 & $1.06(1.05-1.06)$ \\
\hline Veins & $1.06(1.05-1.08)$ & $1.05(1.05-1.06)$ & 0.4 & $1.06(1.05-1.06)$ \\
\hline Median branching points, $n$ (IQR)* & $34.3(30.0-39.0)$ & $27.0(24.0-29.0)$ & 0.0003 & $34.2(32.5-35.6)$ \\
\hline \multicolumn{5}{|l|}{ Median optic papilla areas, $\mathrm{mm}^{2}$ (IQR) } \\
\hline Disc & $1.22(1.11-1.47)$ & $1.18(1.06-1.35)$ & 0.6 & ND \\
\hline Cup & $0.12(0.07-0.35)$ & $0.00(0.00-0.12)$ & 0.058 & ND \\
\hline Rim & $1.17(1.01-1.32)$ & $1.17(1.03-1.30)$ & 0.9 & ND \\
\hline \multicolumn{5}{|l|}{ Retinal examination, $n(\%)$} \\
\hline Normal medical retina & $18(69.2)$ & $13(100)$ & & $32(82.1)$ \\
\hline Grade 1 hypertensive retinopathy & $2(7.7)$ & 0 & & $2(5.1)$ \\
\hline $\begin{array}{l}\text { Pre-proliferative diabetic } \\
\text { retinopathy }\end{array}$ & $3(11.5)$ & 0 & & $2(5.1)$ \\
\hline Proliferative diabetic retinopathy & 0 & 0 & & $3(7.7)$ \\
\hline Glaucoma & $1(3.8)$ & 0 & & 0 \\
\hline Macula abnormalities & $2(7.7)$ & 0 & & $2(5.1)$ \\
\hline
\end{tabular}

*An adjusted model (adjusted for age and sex) showed a similar significant difference between the groups $(P=0.0022)$.

\section{Effect of Acromegaly treatment}

In 16 patients after a median follow-up of 1 year (range, 0.8-3.5) after primary treatment, the tortuosity of the vessels and retinal fundus abnormalities were unchanged. Patients still had a higher median (IQR) number of retinal vascular branching points than controls (35 (27.5-38.5) vs 27 (23.3-29.0), respectively). There was no difference in branching points between the patients that obtained biochemical control and those who did not $(P=0.30)$ (Fig. $2)$. The variation in branching points in the acromegalic population was larger than in the healthy controls. This is reflected in the large IQR shown in Fig. 3.

\section{Cross-sectional study of patients with acromegaly and diabetes}

In 39 patients with known acromegaly for a median (IQR) of 14 years (10-19) and a type $2 \mathrm{DM}$ diagnosis for a median of 14 years (4-19.5), morphometric analysis of retinal vessels confirmed findings of the longitudinal study. Patients had increased number of branching points but unchanged tortuosity of the vessels (Table $2)$. In this cohort, diabetic retinopathy was diagnosed in five (13\%) patients (two pre-proliferative and three proliferative diabetic retinopathy), with two having grade 1 hypertensive retinopathy and two having macular abnormalities. Medical retinal examination was normal in 32 patients. Individuals with diabetic retinopathy from both cohorts had a tendency toward higher mean (S.D.) systolic blood pressure compared to other patients $(141.6 \pm 9.9$ vs $135.1 \pm 11.1 \mathrm{mmHg}, P=0.06)$.

For comparison, data obtained from the Swedish Diabetes Registry for patients with type $2 \mathrm{DM}$ and a DM duration of 7-14 years treated in primary care showed a prevalence of diabetic retinopathy of $21 \%$ in the region around Gothenburg (Västra Götaland) and 24\% at the Swedish national level.

\section{Discussion}

We have shown that patients with acromegaly have an increased number of retinal vascular branching points, suggesting that this is an effect of long-standing excessive exposure of GH and IGF-1. However, the frequency of diabetic retinopathy among patients with concomitant acromegaly and DM was not higher than that expected for patients with type $2 \mathrm{DM}$ alone.

Few other studies have examined the effects of GH on human microvasculature, as this would require invasive techniques in most organs. However, the skin, just like the eye, allows for direct examination of microvasculature. One such study using nail-fold capillaroscopy found a decreased number of capillaries and increased tortuosity in acromegalic patients, which stands in contrast to our 

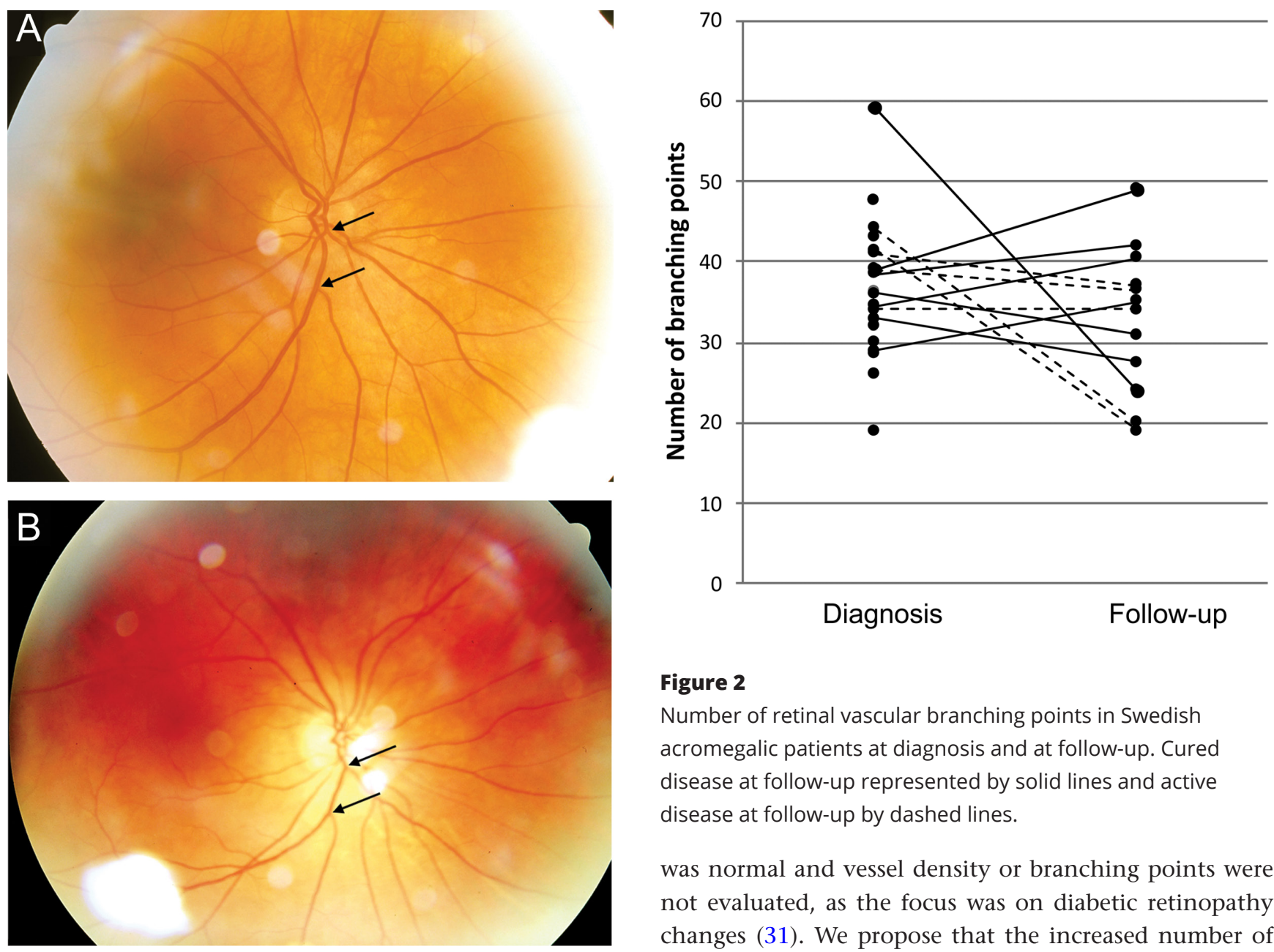

\section{Figure 1}

Fundus photography of (A) patient with acromegaly and (B) healthy control. Examples of branching points marked with arrows.

results from the retina (24). However, such findings in the nail fold are also common in other medical conditions such as hypertension (even subclinical forms) and diabetes, which are both common comorbidities in acromegaly (25). On the other hand, and more in line with our findings, GH-deficient (GHD) patients have reduced skin capillary density and microvascular perfusion, both of which are normalized after 6 months of GH replacement therapy $(26,27)$. Children with GHD (28), GH receptor defects (Laron syndrome) (29), and adult patients with congenital isolated GHD (30) have reduced numbers of branching points in the retina, supporting the hypothesis of a crucial role of the GH/IGF-1 system in vasculogenesis in humans. One cross-sectional study, assessing the safety of long-term GH replacement therapy in adult GHD patients, found no evidence of retinopathy, but in this study serum IGF-1

\section{Figure 2}

Number of retinal vascular branching points in Swedish acromegalic patients at diagnosis and at follow-up. Cured disease at follow-up represented by solid lines and active disease at follow-up by dashed lines.

was normal and vessel density or branching points were not evaluated, as the focus was on diabetic retinopathy changes (31). We propose that the increased number of branching points found in the acromegalic patients in our study may reflect the angiogenic effects of GH/IGF-1 in humans, which might explain some of the effects of GH

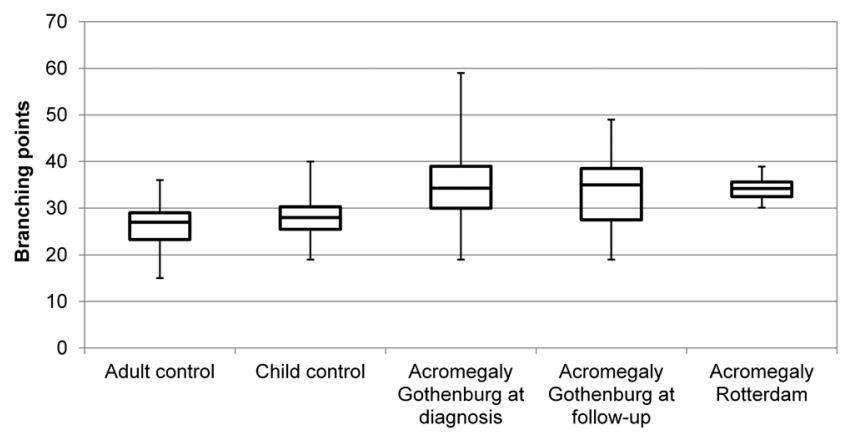

\section{Figure 3}

Number of retinal vascular branching points in healthy adults and children compared to patients with acromegaly from Gothenburg at diagnosis and after 1 year of treatment and patients from Rotterdam. Data are presented as a box and whiskers plot with the interquartile range, median, and maximum and minimum values. 
in other highly vascularized organs such as the thyroid gland (32). As we could detect an increase in branching points after a median of 14 years of optimal treatment, these changes are most likely among the irreversible changes that come with the disease.

The effect of GH on angiogenesis is thought to be direct and indirect through IGF-1. IGF-1 is known to be essential for normal retinal development (33). GH can directly stimulate endothelial proliferation, migration, and extracellular matrix production as well as the formation of capillary structures in vitro (34). Also, GH treatment increases vascularization in the brain (35) and heart (36) of aged rats. Endothelial cells themselves produce little IGF-1, but express IGF-1 receptors and thus respond to circulating IGF-1 (37). IGF-1 promotes angiogenesis by promoting chemotaxis in vitro (38). The angiogenic effects by IGF-1 are thought to be both direct and through stimulation of vascular endothelial growth factor $(39,40)$. It is known that other angiogenic factors in the blood, such as angiogenin and endostatin, are elevated in acromegaly (41) but also in several other physiological and clinical settings (42). This underscores the complexity of angiogenesis and might explain some overlap in branching points in our study groups and control groups. Whether the elevated intraocular IGF-1 in diabetic retinopathy is due to leakage across the bloodretina barrier or represents intraocular production remains a subject of debate $(11,43)$.

We report on a total of 46 patients with acromegaly and DM, eight of whom had some degree of diabetic retinopathy. The overall prevalence of diabetic retinopathy was thus $17 \%$, with the prevalence being higher in the Gothenburg patients $(3 / 7,43 \%)$ than in the Rotterdam patients $(5 / 39,13 \%)$. One difference between the two cohorts is the treatment regime for acromegaly. Most of the Swedish patients received surgery and, if not cured, they received a somatostatin receptor ligand (SRL), whereas most Dutch patients received pegvisomant in addition to SRL (Table 1). GH receptor blockade by pegvisomant may therefore have favorable effects on diabetic retinopathy, although this was not supported by a 24 -week treatment trial in patients with DM and retinopathy (44).

In the general diabetic population, the prevalence of diabetic retinopathy varies locally and over time and direct comparison is therefore difficult. Data from the Swedish National Diabetes Register show a prevalence of retinopathy after a similar duration of diabetes in primary care patients to be just above $20 \%$. We did not have access to detailed population based data from the Netherlands on diabetes retinopathy; however, one study from the city of Einthoven found a prevalence of diabetes retinopathy of $31 \%$ after a median disease duration of 12.5 years (45). These patients, however, were referred to specialists due to a complicated medical situation that could explain the higher prevalence of retinopathy. Taken together, our data do not support the hypothesis of a higher prevalence of diabetic retinopathy in patients with acromegaly and DM. In a recent retrospective study including 16 patients with acromegaly and diabetes, prevalence of proliferative diabetic retinopathy was similar to matched controls with diabetes, whereas no patient had pre-proliferative retinopathy (46). In our study, half of the patients with diabetic retinopathy had pre-proliferative retinopathy. Together these data do not support the hypothesis of IGF-1 exclusively playing a role in proliferative retinopathy. Interestingly, in our patients there was no correlation between blood glucose OGTT results and the number of branching points in retinal vessels. Also, the increased number of branching points was also present in the patients treated with pegvisomant, suggesting that blocking the GH receptor has no effect on this finding.

The impact of acromegaly on diabetic retinopathy may be more complicated than the mere effects of GH and IGF-1 on vascularization as many factors influence the development of retinopathy, not all of which are aggravated by acromegaly. For example, it is well known that markers of inflammation such as C-reactive protein and interleukin- 6 are elevated in diabetic patients with retinopathy compared to patients without retinopathy and are even positively correlated with the severity of retinopathy (47). However, in acromegaly, acutephase reactants are decreased, suggesting that GH/IGF-1 may have anti-inflammatory effects that potentially counteract the development of retinopathy (48). It could be argued that the increased number of retinal vessels in acromegaly might be due to increased blood pressure, altered body composition, or other comorbidities common in acromegaly. We could not find any such correlations in our data. Our conclusion is, therefore, that the increase in vascularization of the retina in both diabetic and non-diabetic patients with acromegaly is a direct effect of increased hormone levels leading to formation of new but seemingly healthy vessels without a significant impact on the development of diabetic retinopathy.

This study has both strengths and limitations. It includes a relatively large number of patients with acromegaly and is based on all available patients treated in the two study centers. The Swedish part of the study was designed in a prospective manner. Limitations of our 
study are that the retinal photographs in our patients and the adult control group were taken with different cameras and at a different location than the retinal photographs of the child cohort, which has been previously published (18). Camera settings and magnification factors were the same for all Swedish patients. However, the tortuosity index, which is dependent on magnification, seemed to differ between the child and the adult control groups, which is why the data from the child cohort was used with caution. The number of branching points is less dependent on minor differences in magnification and the two control groups showed similar results, both of which were significantly different from the acromegalic patients. As the technique of fundus photographs and analysis was different for the Rotterdam patients, fundus morphology data could not be directly compared between the two cohorts of patients with acromegaly.

In conclusion, this unique study shows by objective measures that patients with acromegaly have increased retinal vascular density with apparently normal vessels and that those subjects with diabetes had a prevalence of diabetic retinopathy equal to or lower than what would be expected. The findings support the role for the $\mathrm{GH} /$ IGF-1 system in angiogenesis but not in the development and progress of diabetic retinopathy.

\section{Declaration of interest}

D S O has been a consultant for Sandoz, Ipsen, and Pfizer. G J has been a consultant for AstraZeneca, Novo Nordisk, and Shire and has received lecture fees from Merck Serono, Novo Nordisk, Novartis, Otsuka, Pfizer, and Shire. S N has been a consultant for Pfizer and Ipsen and has received study grants from Pfizer, Novartis, and Ipsen. A H is a medical consultant for Takeda/Shire. G J is on the editorial board of EJE. G J was not involved in the review or editorial process for this paper, on which he is listed as an author. The other authors have nothing to disclose.

\section{Funding}

This research was supported by the Swedish federal government under the ALF agreement on medical training and research (ALFGBG-719531) and an unrestricted grant from Novartis. The sponsors did not take part in the design and conduct of the study, in the collection, management, analysis, and interpretation of data, or in the writing and the decision to submit the manuscript.

\section{Author contribution statement}

A Hellström and $G$ Johannsson contributed equally to this work.

\section{Acknowledgements}

The authors would like to thank the staff at the Centre for Endocrinology and Metabolism at the Department of Endocrinology at Sahlgrenska University Hospital for their excellent collaboration.

\section{References}

1 Esposito D, Ragnarsson O, Granfeldt D, Marlow T, Johannsson G \& Olsson DS. Decreasing mortality and changes in treatment patterns in patients with acromegaly from a nationwide study. European Journal of Endocrinology 2018178 459-469. (https://doi.org/10.1530/ EJE-18-0015)

2 Holdaway IM, Bolland MJ \& Gamble GD. A meta-analysis of the effect of lowering serum levels of GH and IGF-I on mortality in acromegaly. European Journal of Endocrinology 2008159 89-95. (https://doi.org/10.1530/EJE-08-0267)

3 Moller N, Jorgensen JO, Abildgard N, Orskov L, Schmitz O \& Christiansen JS. Effects of growth hormone on glucose metabolism. Hormone Research 199136 (Supplement 1) 32-35. (https://doi. org/10.1159/000182185)

4 Lesen E, Granfeldt D, Houchard A, Dinet J, Berthon A, Olsson DS, Bjorholt I \& Johannsson G. Comorbidities, treatment patterns and cost-of-illness of acromegaly in Sweden: a register-linkage population-based study. European Journal of Endocrinology 2017176 203-212. (https://doi.org/10.1530/EJE-16-0623)

5 Ikram MK, Cheung CY, Lorenzi M, Klein R, Jones TL, Wong TY \& NIH/JDRF Workshop on Retinal Biomarker for Diabetes Group. Retinal vascular caliber as a biomarker for diabetes microvascular complications. Diabetes Care 201336 750-759. (https://doi. org $/ 10.2337 /$ dc12-1554)

6 Bereket A, Lang CH \& Wilson TA. Alterations in the growth hormone-insulin-like growth factor axis in insulin dependent diabetes mellitus. Hormone and Metabolic Research 199931 172-181. (https://doi.org/10.1055/s-2007-978716)

7 Jehle PM, Jehle DR, Mohan S \& Bohm BO. Serum levels of insulinlike growth factor system components and relationship to bone metabolism in Type 1 and type 2 diabetes mellitus patients. Journal of Endocrinology 1998159 297-306. (https://doi.org/10.1677/ joe.0.1590297)

8 Lewitt MS, Dent MS \& Hall K. The insulin-like growth factor system in obesity, insulin resistance and type 2 diabetes mellitus. Journal of Clinical Medicine 20143 1561-1574. (https://doi.org/10.3390/ jcm3041561)

9 Payne JF, Tangpricha V, Cleveland J, Lynn MJ, Ray R \& Srivastava SK. Serum insulin-like growth factor-I in diabetic retinopathy. Molecular Vision 201117 2318-2324.

10 Dills DG, Moss SE, Klein R \& Klein BE. Association of elevated IGF-I levels with increased retinopathy in late-onset diabetes. Diabetes 199140 1725-1730. (https://doi.org/10.2337/diab.40.12.1725)

11 Frystyk J. The growth hormone hypothesis - 2005 revision. Hormone and Metabolic Research 200537 (Supplement 1) 44-48. (https://doi. org/10.1055/s-2005-861362)

12 Poulsen JE. Recovery from retinopathy in a case of diabetes with Simmonds' disease. Diabetes 19532 7-12. (https://doi.org/10.2337/ diab.2.1.7)

13 Teuscher A, Escher F, Konig H \& Zahnd G. Long-term effects of transsphenoidal hypophysectomy on growth hormone, renal function and eyeground in patients with diabetic retinopathy. Diabetes 197019 502-518. (https://doi.org/10.2337/diab.19.7.502)

14 Ballintine EJ, Foxman S, Gorden P \& Roth J. Rarity of diabetic retinopathy in patients with acromegaly. Archives of Internal Medicine 1981141 1625-1627.

15 Amemiya T, Toibana M, Hashimoto M, Oseko F \& Imura H. Diabetic retinopathy in acromegaly. Ophthalmologica 1978176 74-80. (https://doi.org/10.1159/000308696)

16 Azzoug S \& Chentli F. Diabetic retinopathy in acromegaly. Indian Journal of Endocrinology and Metabolism 201418 407-409. (https:// doi.org/10.4103/2230-8210.131207)

17 Rimmer S, Keating C, Chou T, Farb MD, Christenson PD, Foos RY $\&$ Bateman JB. Growth of the human optic disk and nerve during gestation, childhood, and early adulthood. American Journal of 
Ophthalmology 1993116 748-753. (https://doi.org/10.1016/s00029394(14)73476-2)

18 Hellstrom A \& Svensson E. Optic disc size and retinal vessel characteristics in healthy children. Acta Ophthalmologica Scandinavica 199876 260-267. (https://doi.org/10.1034/j.16000420.1998.760302.x)

19 The Swedish National Diabetes Register. Ett knapptryck för förbättringsarbete 2019, Mar 9. (available at: https://www.ndr.nu/\#/ knappen)

20 Elmlinger MW, Kuhnel W, Weber MM \& Ranke MB. Reference ranges for two automated chemiluminescent assays for serum insulin-like growth factor I (IGF-I) and IGF-binding protein 3 (IGFBP-3). Clinical Chemistry and Laboratory Medicine 200442 654-664. (https://doi. org/10.1515/CCLM.2004.112)

21 Bidlingmaier M, Friedrich N, Emeny RT, Spranger J, Wolthers OD, Roswall J, Korner A, Obermayer-Pietsch B, Hubener C, Dahlgren J et al. Reference intervals for insulin-like growth factor-1 (IGF-I) from birth to senescence: results from a multicenter study using a new automated chemiluminescence IGF-I immunoassay conforming to recent international recommendations. Journal of Clinical Endocrinology and Metabolism 201499 1712-1721. (https://doi. org/10.1210/jc.2013-3059)

22 Stromland K, Hellstrom A \& Gustavsson T. Morphometry of the optic nerve and retinal vessels in children by computer-assisted image analysis of fundus photographs. Graefe's Archive for Clinical and Experimental Ophthalmology 1995233 150-153. (https://doi. org/10.1007/bf00166607)

23 Walsh JB. Hypertensive retinopathy. Description, classification, and prognosis. Ophthalmology 198289 1127-1131. (https://doi. org/10.1016/S0161-6420(82)34664-3)

24 Schiavon F, Maffei P, Martini C, De Carlo E, Fais C, Todesco S \& Sicolo N. Morphologic study of microcirculation in acromegaly by capillaroscopy. Journal of Clinical Endocrinology and Metabolism 1999 84 3151-3155. (https://doi.org/10.1210/jcem.84.9.5952)

25 Lambova SN \& Muller-Ladner U. The specificity of capillaroscopic pattern in connective autoimmune diseases. A comparison with microvascular changes in diseases of social importance: arterial hypertension and diabetes mellitus. Modern Rheumatology 200919 600-605. (https://doi.org/10.1007/s10165-009-0221-x)

26 Oomen PH, Beentjes JA, Bosma E, Smit AJ, Reitsma WD \& Dullaart RP. Reduced capillary permeability and capillary density in the skin of GH-deficient adults: improvement after 12 months GH replacement. Clinical Endocrinology 200256 519-524. (https://doi. org/10.1046/j.1365-2265.2002.01517.x)

27 Hana V, Prazny M, Marek J, Skrha J \& Justova V. Reduced microvascular perfusion and reactivity in adult GH deficient patients is restored by GH replacement. European Journal of Endocrinology 2002 147 333-337. (https://doi.org/10.1530/eje.0.1470333)

28 Hellstrom A, Svensson E, Carlsson B, Niklasson A \& AlbertssonWikland K. Reduced retinal vascularization in children with growth hormone deficiency. Journal of Clinical Endocrinology and Metabolism 199984 795-798. (https://doi.org/10.1210/ jcem.84.2.5484)

29 Hellstrom A, Carlsson B, Niklasson A, Segnestam K, Boguszewski M, de Lacerda L, Savage M, Svensson E, Smith L, Weinberger D et al. IGF-I is critical for normal vascularization of the human retina. Journal of Clinical Endocrinology and Metabolism 200287 3413-3416. (https://doi.org/10.1210/jcem.87.7.8629)

30 Pereira-Gurgel VM, Faro AC, Salvatori R, Chagas TA, CarvalhoJunior JF, Oliveira CR, Costa UM, Melo GB, Hellstrom A \& AguiarOliveira MH. Abnormal vascular and neural retinal morphology in congenital lifetime isolated growth hormone deficiency. Growth Hormone and IGF Research 2016 30-31 11-15. (https://doi. org/10.1016/j.ghir.2016.07.001)
31 Blank D, Riedl M, Reitner A, Schnack C, Schernthaner G, Clodi M, Frisch $\mathrm{H} \&$ Luger A. Growth hormone replacement therapy is not associated with retinal changes. Journal of Clinical Endocrinology and Metabolism 200085 634-636. (https://doi.org/10.1210/ jcem.85.2.6403)

32 Bogazzi F, Manetti L, Bartalena L, Gasperi M, Grasso L, Cecconi E, Rago T, Pinchera A \& Martino E. Thyroid vascularity is increased in patients with active acromegaly. Clinical Endocrinology 200257 65-70. (https://doi.org/10.1046/j.1365-2265.2002.01562.x)

33 Liegl R, Lofqvist C, Hellstrom A \& Smith LE. IGF-1 in retinopathy of prematurity, a CNS neurovascular disease. Early Human Development 2016102 13-19. (https://doi.org/10.1016/j.earlhumdev.2016.09.008)

34 Messias de Lima CF, Dos Santos Reis MD, da Silva Ramos FW, AyresMartins S \& Smaniotto S. Growth hormone modulates in vitro endothelial cell migration and formation of capillary-like structures. Cell Biology International 201741 577-584. (https://doi.org/10.1002/ cbin.10747)

35 Sonntag WE, Lynch CD, Cooney PT \& Hutchins PM. Decreases in cerebral microvasculature with age are associated with the decline in growth hormone and insulin-like growth factor 1. Endocrinology 1997 138 3515-3520. (https://doi.org/10.1210/endo.138.8.5330)

36 Khan AS, Lynch CD, Sane DC, Willingham MC \& Sonntag WE. Growth hormone increases regional coronary blood flow and capillary density in aged rats. Journals of Gerontology: Series A, Biological Sciences and Medical Sciences 200156 B364-B371. (https:// doi.org/10.1093/gerona/56.8.b364)

37 Tucci M, Nygard K, Tanswell BV, Farber HW, Hill DJ \& Han VK. Modulation of insulin-like growth factor (IGF) and IGF binding protein biosynthesis by hypoxia in cultured vascular endothelial cells. Journal of Endocrinology 1998157 13-24. (https://doi. org/10.1677/joe.0.1570013)

38 Shigematsu S, Yamauchi K, Nakajima K, Iijima S, Aizawa T \& Hashizume K. IGF-1 regulates migration and angiogenesis of human endothelial cells. Endocrine Journal 199946 (Supplement) S59-S62. (https://doi.org/10.1507/endocri.46.suppl_s59)

39 Smith LE, Shen W, Perruzzi C, Soker S, Kinose F, Xu X, Robinson G, Driver S, Bischoff J, Zhang B et al. Regulation of vascular endothelial growth factor-dependent retinal neovascularization by insulin-like growth factor-1 receptor. Nature Medicine 19995 1390-1395. (https:// doi.org/10.1038/70963)

40 Miele C, Rochford JJ, Filippa N, Giorgetti-Peraldi S \& Van Obberghen E. Insulin and insulin-like growth factor-I induce vascular endothelial growth factor mRNA expression via different signaling pathways. Journal of Biological Chemistry 2000275 21695-21702. (https://doi.org/10.1074/jbc.M000805200)

41 Silha JV, Krsek M, Hana V, Marek J, Weiss V, Jezkova J, Rosicka M, Jarkovska Z \& Murphy LJ. The effects of growth hormone status on circulating levels of vascular growth factors. Clinical Endocrinology 200563 79-86. (https://doi.org/10.1111/j.1365-2265.2005.02303.x)

42 Yu D, Cai Y, Zhou W, Sheng J \& Xu Z. The potential of angiogenin as a serum biomarker for diseases: systematic review and metaanalysis. Disease Markers 20182018 1984718. (https://doi. org/10.1155/2018/1984718)

43 Wilkinson-Berka JL, Wraight C \& Werther G. The role of growth hormone, insulin-like growth factor and somatostatin in diabetic retinopathy. Current Medicinal Chemistry 200613 3307-3317. (https://doi.org/10.2174/092986706778773086)

44 Growth Hormone Antagonist for Proliferative Diabetic Retinopathy Study Group. The effect of a growth hormone receptor antagonist drug on proliferative diabetic retinopathy. Ophthalmology 2001108 2266-2272. (https://doi.org/10.1016/s0161-6420(01)00853-3)

45 van Herpt TTW, Lemmers RFH, van Hoek M, Langendonk JG, Erdtsieck RJ, Bravenboer B, Lucas A, Mulder MT, Haak HR, Lieverse AG et al. Introduction of the DiaGene study: clinical 
characteristics, pathophysiology and determinants of vascular complications of type 2 diabetes. Diabetology and Metabolic Syndrome 20179 47. (https://doi.org/10.1186/s13098-017-0245-x)

$46 \mathrm{Wu}$ TE \& Chen HS. Increased prevalence of proliferative retinopathy in patients with acromegaly. Journal of the Chinese Medical Association 201881 230-235. (https://doi.org/10.1016/j.jcma.2017.09.013)

47 Song J, Chen S, Liu X, Duan H, Kong J \& Li Z. Relationship between C-reactive protein level and diabetic retinopathy: a systematic review and meta-analysis. PLoS ONE 201510 e0144406. (https://doi. org/10.1371/journal.pone.0144406)

48 Andreassen M, Vestergaard H \& Kristensen LØ. Concentrations of the acute phase reactants high-sensitive $\mathrm{C}$-reactive protein and YKL- 40 and of interleukin- 6 before and after treatment in patients with acromegaly and growth hormone deficiency. Clinical Endocrinology 200767 909-916. (https://doi.org/10.1111/j.13652265.2007.02986.x)

Received 29 September 2019

Revised version received 5 December 2019

Accepted 8 January 2020 